\title{
Factors associated with severity of symptoms in patients with chronic unexplained muscular aching
}

\author{
EDWARD KOLAR, ARTHUR HARTZ, ALAN ROUMM, \\ LAWRENCE RYAN, ROBERT JONES, AND ELAINE KIRCHDOERFER
}

From the Department of Family and Community Medicine and Department of Medicine, the Milton $S$ Hershey Medical Center, the Pennsylvania State University, Hershey, Pennsylvania

SUMMARY Subjects with chronic, diffuse, unexplained muscular aching were recruited-21 from a primary care practice, nine from a rheumatology practice, and two from a pain clinic. No additional criteria were used to select subjects. Subjects with mild or moderate symptoms differed from those with severe symptoms with respect to the following characteristics: the presence of fatigue on awakening, the number of tender points, difficulty in sleeping, and the degree of tenderness in typical fibromyalgic areas as measured by a dolorimeter. These findings suggest that muscular aching is likely to be of greater severity if other symptoms or signs of fibromyalgia are also present.

Key words: fibromyalgia, soft tissue rheumatism, tender points, sleep disorder.

Fibromyalgia is a syndrome whose primary symptom is chronic diffuse unexplained muscular aching. Other features of the syndrome include sleep disturbance, predictable sites of localised tenderness, and a high sensitivity to exogenous / modulating factors. ${ }^{12}$ As there is no pathognomonic feature for fibromyalgia there has been considerable debate as to what criteria are essential for diagnosis. In particular, interest has focused on the diagnostic value of tender points: which points should be assessed and how many are necessary to establish the diagnosis. ${ }^{3-6}$ Some investigators believe that the presence of tender points is an indispensable condition. $^{7}$

In this study we examine the way in which the criteria for fibromyalgia relate to the severity of symptoms in the general group of patients who have chronic, diffuse, unexplained muscular aching. Many of the patients in this study did not meet other criteria for fibromyalgia. The results indicate which features of the fibromyalgia syndrome are most important in identifying patients with severe disease.

\section{Patients and methods}

RECRUITMENT OF SUBJECTS

The 32 patients for this study were recruited from

Accepted for publication 1 October 1988.

Correspondence to Dr Arthur Hartz, Division of Epidemiology, Medical College of Wisconsin, PO Box 26509, Milwaukee, Wisconsin 53226, USA. three sources: 21 from a hospital based family medicine clinic, nine from a private rheumatology practice, and two from a hospital based pain clinic. All patient contact and evaluation was conducted by the same person (EK). Patients from the rheumatology practice had been treated within the past six months for soft tissue rheumatism with no identifiable cause. Patients from the family medicine and pain clinics were initially identified in an epidemiology study of chronic, diffuse, unexplained muscular aching. ${ }^{8}$ They had been screened by questionnaire, personal interview, physical examination, and review of the medical records. No laboratory tests were performed for the purposes of this study, but all available medical records were reviewed, and subjects were excluded if laboratory tests or $x$ rays provided a possible explanation for the subjects' symptoms. The presence of tender points was not used to identify subjects for this study.

All subjects agreeing to participate in the study were required to meet the following criteria: $(a)$ age between 21 and 70 years; $(b)$ muscular aching or stiffness, or both in at least three distinct locations; (c) symptoms of greater than three months' duration; (d) symptoms not secondary to osteoarthritis or other diagnoses, such as trauma, tendinitis, bursitis, inflammatory disease, or hypothyroidism.

I N F ORM ATION OBTAINED

Subjects completed an extensive questionnaire that 
provided the following information: demographic data, severity of muscle aching, problems with sleeping, presence of fatigue on awakening, frequency of aching and stiffness on awakening, presence of symptoms related to somatisation, and effects of various modulating factors on the degree of their muscle aching.

Muscle aching was assessed by the response to the question: 'Please record the degree of muscle aching'. The subjects were asked to circle a response on a five point scale from absent to severe. Responses were divided into two categories on the basis of severity: (1) mild or moderate muscle aching and (2) moderately severe or severe aching. Although there is likely to be some overlap between the moderate and moderately severe responses, subjects in group 2 should in general have more severe symptoms than those in group 1.

Subjects were asked if they had any of the following problems with sleeping: falling asleep, waking frequently, or waking early. For each of these questions there were three possible responses: rarely or never, sometimes, or frequently (a quarter of the time or more). Subjects were considered to have problems sleeping if they responded that they had any of these problems frequently.

The symptom of non-restorative sleep was assessed by asking the subjects: 'In general, how do you feel after you wake up in the morning?' There were four possible responses to this question: refreshed, mildly fatigued, moderately fatigued, or severely fatigued. Subjects who chose either of the last two responses were considered to have non-restorative sleep.

To evaluate the presence of somatisation disorder we asked the subjects about the presence of symptoms that have previously been shown to be associated with this disorder ${ }^{9}$ : faintness, abdominal fullness, dizziness, pain or fullness in the chest, shortness of breath, pounding heart, numbness, headaches, and abdominal pain relieved by bowel movement. Each of these symptoms was scored as a '0' (rarely or never), ' 1 ' (occasionally), or ' 2 ' (frequently). A subject was considered to have one of the above symptoms if the symptom was recorded as occurring frequently. An average score for all the somatisation symptoms was also calculated for each subject.

Factors that have been reported to modulate the symptoms of fibrositis ${ }^{4}$ were assessed for their ability to improve or worsen muscle symptoms. The factors studied included cold, damp, hot, and dry weathef, physical activity, emotional tension, fatigue, rest, recreation, menstruation, pregnancy, and heat application.

ASSESSMENT OF TENDER POINTS

The physical examination consisted of measurement of height and weight, inspection for obvious physicater abnormality, and assessment for tender points Table 1 lists the areas assessed for tender points $\stackrel{\mathscr{P}}{\rightarrow}$ These areas were defined by Campbell et al.을 Eighteen of these areas are considered typica locations for tender points in patients with fibro- $-\frac{\bar{s}}{6}$ myalgia, and the remaining seven locations werę used as control sites.

Each of the 25 defined areas was assessed for tender points both by palpation and with the aid of the dolorimeter. An area was considered to be $\vec{a}_{\omega}$ discrete tender point by palpation only when it was reported as significantly more tender than the surrounding areas.

The value of a dolorimeter for measuring pressure sensitivity has been described elsewhere. ${ }^{11}$ Thei device we used was a simple spring loaded scale $\overrightarrow{-}$ $(0.00-4.50 \mathrm{~kg})$ with a $0.95 \mathrm{~cm}^{2}$ flat round metal tip.을 It was used to apply a specified amount of pressureto any given point. If discrete tender points weres identified the dolorimeter was then applied specifically to them, otherwise it was applied to the centre of the tender point area. The dolorimeter was thenog depressed and the patient asked to identify when the pressure began to hurt (tenderness level A) ando when the pain became unbearable (tenderness leves B). It was stressed that this was an evaluation of the patient's sensitivity to pressure rather than of theo patient's ability to tolerate or endure the pressure.을 The pressure was discontinued when the patient $\overrightarrow{0}$ acknowledged unbearable discomfort verbally or by 3 flinching, grimacing, or withdrawal. We then recorded the absence or presence of discrete points $s^{0}$. of tenderness, the pressure levels associated witho pain, and the nature of the patient's response.

Subjects with severe muscle aching were compared?

Table 1 Description of the principal areas examined for tender points

\section{Fibrositic areas}

Occiput: $2 \mathrm{~cm}$ below occipital crest, $1 \mathrm{~cm}$ lateral to midline

Intertransverse ligaments: posterior to transverse processes $44-6 \mathrm{O}$

Trapezius: midpoint of upper border

Paraspinous: $3 \mathrm{~cm}$ lateral to midline at level of mid-scapula

Second costochondral junction: upper border of second rib jusic lateral to costochondral junction

Elbow: $1-2 \mathrm{~cm}$ distal to lateral epicondylc over or distal to insertion of finger extensors

Lumbar spine: midline over interspinous ligaments L4-S1

Gluteus: upper half of mid-gluteus medius

Medial knee: between joint line and adductor tubercle

Control areas

Forehead: midline just below scalp line

Forearm: volar aspect mid-forearm

Thumb: over thumbnail with thumb placed on table

Shin: over bony prominence of mid-shin 
with those with mild or moderate aching on the basis of each of the following tender point counts: $(a)$ the number of discrete tender points found in all 25 areas tested (see Table 1); $(b)$ the number of discrete tender points in the seven control areas (see Table 1); $(c)$ the number of discrete tender points in the 18 fibrositic areas (see Table 1); $(d)$ the number of tender points in the same 18 areas using the definition of tender point as a maximum tolerable dolorimeter reading below a threshold of $2.60 \mathrm{~kg} / \mathrm{cm}^{2}$. This threshold is the same pressure per square centimetre as that used by Campbell et al, ${ }^{4}$ though the tips of the dolorimeters used in the two studies differed.

In addition to the number of tender points we also constructed four indices of tenderness based on dolorimeter readings: $(a)$ the averages of pressures recorded at all locations when the patient first noted pain or discomfort (tenderness level $\mathrm{A}$ ); $(b)$ the average pressures for all locations when the degree of applied pressure became unbearable (tenderness level B); $(c)$ the average tenderness level B for traditional fibromyalgia locations; $(d)$ the average tenderness level $\mathrm{B}$ for control locations.

\section{STATISTICAL METHODS}

Each categorical symptom was tested for an association with severity of muscle aching using the $\chi^{2}$ contingency table analysis without correcting for continuity. Ordinal variables were tested for an association with the severity of muscle aching using the Wilcoxon rank sum test. Logistic regression with SAS statistical programs ${ }^{12}$ was used to determine whether a combination of patient characteristics was more predictive of degree of muscle aching than any one characteristic alone.

\section{Results}

Twenty eight of the 32 subjects were women. Four subjects had less than a high school education, and four subjects completed college. The age of the subjects ranged from 21 to 66 years (mean 41.2). Duration of symptoms ranged from one to 27 years (mean 9.1). Age of onset of the symptoms was less than age 20 for $26 \%$ of the subjects and more than age 40 for $24 \%$ of the subjects.

Tables 2 and 3 present the association between the degree of muscle aching and a number of patient characteristics. There were statistically significant associations between muscle aching and the following patient characteristics: number of areas with discrete tender points, number of tender points as defined by sensitivity to dolorimeter pressure below a given threshold, degree of tenderness as determined by the dolorimeter in all 25 sites or for the fibromyalgia
Table 2 Mean levels of characteristics associated with the fibrositis syndrome

\begin{tabular}{|c|c|c|c|}
\hline \multirow[t]{2}{*}{ Characteristic } & \multicolumn{2}{|c|}{ Degree of muscle aching } & \multirow[t]{2}{*}{$p$ Value } \\
\hline & $\begin{array}{l}\text { Mild to } \\
\text { moderate } \\
(n=17)\end{array}$ & $\begin{array}{l}\text { Moderately } \\
\text { severe to } \\
\text { severe } \\
(n=15)\end{array}$ & \\
\hline $\begin{array}{l}\text { Number of discrete } \\
\text { tender points } \\
\text { (all points) }\end{array}$ & $\begin{array}{l}12.3 \\
\quad(n=16)\end{array}$ & 17.3 & $<0.03$ \\
\hline $\begin{array}{l}\text { Number of tender points } \\
\text { based on dolorimetert }\end{array}$ & $6 \cdot 7$ & $11 \cdot 0$ & $<0 \cdot 03$ \\
\hline $\begin{array}{l}\text { Dolorimeter pressure } \\
\text { all areas (TLA) } \ddagger \\
\left(\mathrm{kg} / \mathrm{cm}^{2}\right)\end{array}$ & $2 \cdot 5$ & 1.9 & $<0 \cdot(04$ \\
\hline $\begin{array}{l}\text { Dolorimeter pressure } \\
\text { all areas (TLB) } \ddagger \\
\left(\mathrm{kg} / \mathrm{cm}^{2}\right)\end{array}$ & $3 \cdot 3$ & $2 \cdot 8$ & $<0 \cdot 04$ \\
\hline $\begin{array}{l}\text { Dolorimeter pressure } \\
\text { fibrositic areas (TLB) } \\
\left(\mathrm{kg} / \mathrm{cm}^{2}\right)\end{array}$ & $3 \cdot 2$ & $2 \cdot 5$ & $<0 \cdot 04$ \\
\hline $\begin{array}{l}\text { Dolorimeter pressure } \\
\text { control areas (TLB) } \\
\left(\mathrm{kg} / \mathrm{cm}^{2}\right)\end{array}$ & $3 \cdot 8$ & $3 \cdot 4$ & NS \\
\hline Somatisation score & $\begin{array}{l}0.75 \\
(n=14)\end{array}$ & $\begin{array}{l}0 \cdot 69 \\
(n=14)\end{array}$ & NS \\
\hline
\end{tabular}

*The Wilcoxon rank sum test was used to determine $p$ values. NS indicates $\mathrm{p}>0 \cdot 1$.

†An area was considered a tender point if the maximum tolerable pressure at the point was below a threshold of $2.6 \mathrm{~kg} / \mathrm{cm}^{2}$.

$\ddagger T L A=$ tenderness level $A ; T L B=$ tenderness level $B$-see 'Assessment of tender points'.

Table 3 Number (\%) of subjects having a fibrositis characteristic according to degree of muscle aching

\begin{tabular}{|c|c|c|c|}
\hline \multirow[t]{2}{*}{ Characteristic } & \multicolumn{2}{|c|}{ Degree of muscle aching } & \multirow[t]{2}{*}{ p Value } \\
\hline & $\begin{array}{l}\text { Mild to } \\
\text { moderate } \\
(n=17)\end{array}$ & $\begin{array}{l}\text { Moderately } \\
\text { severe to } \\
\text { severe } \\
(n=15)\end{array}$ & \\
\hline $\begin{array}{l}\text { More than } 12 \text { discrete } \\
\text { tender points }\end{array}$ & $\begin{array}{ll}8 & (50) \\
& (n=16)\end{array}$ & $13(87)$ & $<0 \cdot 03$ \\
\hline Slecp problem & $7(41)$ & $12(80)$ & $<0.03$ \\
\hline $\begin{array}{l}\text { Non-restorative sleep } \\
\text { Aching and stiffness }\end{array}$ & $6(35)$ & $13(87)$ & $<0.01$ \\
\hline on awakening & $\begin{array}{l}9(56) \\
\quad(n=16)\end{array}$ & $6(40)$ & NS \\
\hline Headaches & $\begin{array}{l}7(50) \\
(n=14)\end{array}$ & $\begin{array}{l}5(36) \\
(n=14)\end{array}$ & NS \\
\hline $\begin{array}{l}\text { Abdominal pain } \\
\text { relieved by bowel } \\
\text { movement }\end{array}$ & $\begin{array}{l}0(0) \\
\quad(n=16)\end{array}$ & $\begin{array}{l}3(21) \\
(n=14)\end{array}$ & NS \\
\hline Low energy level & $\begin{array}{ll}5 & (36) \\
& (n=14)\end{array}$ & $\begin{array}{l}6(43) \\
(n=14)\end{array}$ & NS \\
\hline
\end{tabular}

${ }^{*}$ The $\chi^{2}$ test was used to determine significance level. NS indicates $\mathrm{p}>0 \cdot 1$. 
sites alone, sleep problems, and non-restorative sleep.

We found no association between the degree of muscle aching and awakening with aching and stiffness, the overall somatisation score or any individual symptom of somatisation, or feeling tired during the day.

Although not shown in these tables, we found that the presence of modulating factors, the age of the subjects, duration of symptoms, or age of onset of symptoms were not associated with severity. We also found that most subjects were affected by modulating factors. A hot shower improved the symptoms of $89 \%$ of the subjects and cold weather, damp weather, fatigue, and overactivity each made the symptoms worse for more than $75 \%$ of the subjects.

The variable most strongly associated with increased muscle aching was non-restorative sleep. We used logistic regression to test whether other factors offered significant additional predictive value when used with the presence of non-restorative sleep. Only the number of discrete tender areas made an additional significant contribution to predicting the severity of muscle aching.

Table 4 gives a distribution of the number of discrete tender points in the 18 areas commonly used to assess tenderness. All of the subjects with severe symtoms had at least 10 tender points but so did most subjects with milder symptoms. To maximise the difference between the two groups in the percentage of subjects with severe aching, we divided the subjects into two groups: those with 13 or more tender points and those with fewer tender points.

Table 5 ilustrates the additive effect of tender points and non-restorative sleep on predicting severe symptoms. Subjects who had more than 12 tender points and who did not have restorative sleep were very likely to have severe symptoms, subjects with neither condition did not have severe symptoms, and those with only one of the conditions had an
Table 5 Factors independently associated with severity oț̣. muscle aching

\begin{tabular}{|c|c|c|c|}
\hline \multirow[t]{2}{*}{$\begin{array}{l}\text { Non-restorative } \\
\text { sleep** }\end{array}$} & \multirow[t]{2}{*}{$\begin{array}{l}13 \text { or more } \\
\text { tender points* }\end{array}$} & \multicolumn{2}{|c|}{$\begin{array}{l}\text { Proportion with } \\
\text { severe symptoms }\end{array}$} \\
\hline & & $\%$ & Number \\
\hline No & No & 0 & $0 / 5$ \\
\hline No & Yes & 25 & $2 / 8$ \\
\hline Yes & No & 40 & $2 / 5$ \\
\hline Yes & Yes & 85 & $11 / 13$ \\
\hline
\end{tabular}

${ }^{*} \mathrm{p}<0.05$ with logistic regression; ${ }^{* *} \mathrm{p}<0.01$ with logistic regression

intermediate chance of severe symptoms. Although subjects who had non-restorative sleep were moreiw likely to have 13 or more tender points, the symptoms often occurred independently of eache other, and both had statistically significant associa-tions with severity of muscle aching in the logistict regression.

\section{Discussion}

Our results suggest that awakening with fatigue ando the number of tender points are significantly and independently associated with the degree of muscleo aching in patients presenting with diffuse chronico muscle aching of unknown aetiology. Although in other studies the number of tender points has been $\overrightarrow{\overrightarrow{5}}$ considered more important than non-restorative 3 sleep, the latter was more significantly associated? with severity of symptoms in our study. In addition? the presence of non-restorative sleep may be morem important clinically than the tender point count because it is information which is more easilys obtained and does not require the setting of an arbitrary threshold value. It was not possible to determine with the information available in our study whether non-restorative sleep was a cause or consequence of the musculoskeletal symptoms.

Symptoms of somatisation disorder were noE

Table 4 Distribution of tender point counts

\begin{tabular}{|c|c|c|c|c|c|c|}
\hline \multirow{3}{*}{$\begin{array}{l}\text { Number of discrete } \\
\text { areas of tenderness* }\end{array}$} & \multicolumn{6}{|c|}{ Degree of muscle aching } \\
\hline & \multicolumn{3}{|c|}{ Mild to moderate } & \multicolumn{3}{|c|}{ Moderately severe to severe } \\
\hline & Number & $\%$ & Cumulative \% & Number & $\%$ & Cumulative \% \\
\hline $0-4$ & 1 & $6 \cdot 25$ & $6 \cdot 25$ & 0 & - & - \\
\hline $5-9$ & 3 & $18 \cdot 75$ & $25 \cdot 0$ & 0 & - & - \\
\hline $10-14$ & 4 & 25.0 & $50 \cdot 0$ & 3 & 20.0 & $20 \cdot 0$ \\
\hline $15-19$ & 5 & $31 \cdot 25$ & $81 \cdot 25$ & 6 & $40 \cdot 0$ & $60 \cdot 0$ \\
\hline $20-23$ & 3 & $18 \cdot 75$ & $100 \cdot 0$ & 6 & $40 \cdot 0$ & $100 \cdot 0$ \\
\hline
\end{tabular}


significantly related to the degree of muscular aching in this study, though the relation may become more apparent with larger samples.

Several factors were found to modulate symptoms for most subjects in this study. There was no association between the degree of the musculoskeletal symptoms and the ability of the modulating factors to affect these symptoms.

The major difference between the design of this study and that of most others evaluating the individual symptoms of the fibromyalgia syndrome is that we selected subjects only on the basis of the musculoskeletal complaint. They were achy patients without identifiable organic musculoskeletal disease. Previous studies compared subjects with strictly defined fibromyalgia with subjects without this condition. $^{4-7}$ These studies found that certain symptoms are much more common in those with fibromyalgia. A limitation of these studies, however, is that the symptoms of fibromyalgia, particularly the presence of a critical number of tender points, were used to identify those with fibromyalgia. Therefore subjects with fibromyalgia necessarily had a greater prevalence of these symptoms than the controls. The circular reasoning involved in these studies has been noted previously. ${ }^{13} 14$

A second difference between our study and most previous studies is that we recruited most patients from a general medical clinic. Therefore, it is likely that many of the subjects in this study had less severe muscular aching and fewer associated symptoms than the subjects in the other studies. The heterogeneity of the patients in this study facilitated a study of factors associated with severity of musculoskeletal symptoms.

Unfortunately, without a gold standard to identify fibromyalgia it is not possible to evaluate the use of certain symptoms in making the diagnosis. Although our design reduces the problem of circular reasoning, the results of our investigation only indirectly relate to the problem of defining fibromyalgia. The study indicates, however, which features of the fibromyalgia syndrome are most associated with severe symptoms.

Our results support the model for fibromyalgia proposed by Masi and Yunus. ${ }^{15}$ In this model the fibromyalgia syndrome is not a discrete entity but a continuum from no tender points and no muscle aching to many tender points and severe muscle aching. Our results suggest that this model should be expanded to include non-restorative sleep and perhaps other factors in the fibromyalgia syndrome. The model suggests that the syndrome of fibrositis has been recognised as a clinical entity because those patients who have many of the features of the syndrome are most likely to have severe symptoms and therefore are most likely to present to the physician. The model does not suggest why the features of the syndrome occur together or whether the musculoskeletal symptoms or the other features of the syndrome represent the primary abnormality. More research is required to answer these questions.

Supported in part by PHS grants 5-D32-PE13013-03, 5-D15PE83003-09, and the Pennsylvania Arthritis Foundation.

\section{References}

1 Smythe H A. Nonarticular rheumatism and the fibrositis syndrome. In: Hollander J L. McCarty D J, eds. Arthritis and allied conditions. 10th ed. Philadelphia: Lea and Febiger, 1985: 1083-93.

2 Smythe H A. Moldofsky H. Two contributions to the understanding of the fibrositis syndrome. Bull Rheum Dis 1977; 28: 928-31.

3 Bennett R M. Fibrositis: misnomer for a common rheumatic disorder. West J Med 1981; 134: 405-13.

4 CampbellS M. Clark S. Tindall E A, Forehand ME, Bennett R M. Clinical characteristics of fibrositis: I. A 'blinded' controlled study of symptoms and tender points. Arthritis Rheum 1983; 26: $817-24$.

5 Wolfe F, Hawley D J, Cathey M A. Caro X, Russell I J. Fibrositis: a symptom frequency and criteria for diagnosis. An evaluation of 291 rheumatic disease patients and 58 normal individuals. $J$ Rheumatol 1985; 12: 1159-63.

6 Yunus M, Masi A T. Calabro J J. Miller K A. Feigenbaum S L. Primary fibromyalgia (fibrositis): clinical study of 50 patients with matched normal controls. Semin Arthritis Rheum 1981; 11: 155-71.

7 Wolfe F. Development of criteria for the diagnosis of fibrositis. Am J Med 1986; 81: 99-104.

8 Hartz A, Kirchdoerfer E. Undetected fibrositis in primary care practice. J Fam Pract 1987; 25: 365-9.

9 Smith G R, Monson R, Ray D. Patients with multiple unexplained symptoms. Their characteristics, functional health, and health care utilization. Arch Intern Med 1986; 146: 69-72.

10 McCarty D J Jr, Gatter R A, Phelps P. A dolorimeter for quantification of articular tenderness. Arthritis Rheum 1965; 8: 551-9.

11 Merskey H, Spear F G. The reliability of the pressure algometer. Br J Soc Psychol 1964; 3: 130-6.

12 SAS Institute Inc. SAS user's guide: statistics. 5 ed. Cary, NC: SAS Institute Inc, 1985.

13 Rice J R. 'Fibrositis' syndrome. Med Clin North Am 1986; 70: 455-68.

14 Bennett R M. Panel discussion III. Am J Med 1986; 81: 71

15 Masi A T, Yunus M V. Concepts of illness in populations as applied to fibromyalgia syndromes. Am J Med 1986; 81: 19-25. 